\title{
How Does Pedagogy Compare between Professional Dance Education and Non-Professional Dance Education
}

\author{
Yingying $\mathrm{Hu}^{*}$ \\ Chengdu Vocational University of Art, Chengdu, Sichuan, 611433, China
}

\begin{tabular}{l} 
ARTICLE INFO \\
\hline Article history \\
Received: 1 April 2021 \\
Revised: 7 April 2021 \\
Accepted: 9 April 2021 \\
Published Online: 16 April 2021
\end{tabular}

Keywords:

Dance education

Professional education

Non-professional education

Pedagogy

\section{Introduction}

Dance education has been popularised at different educational levels including primary, secondary, higher and vocational education $^{[17]}$. This provides more opportunities for dance teachers to teach the subject and for students to learn it. At university, I had the opportunity to teach students of different ages and backgrounds including secondary students, undergraduates, adults and both professionals and non-professionals. However, this created a problem for me as, although I was teaching a variety of people, I did not alter my teaching style. Specifically, I used a style which aimed to foster professional dancers, it was unable to teach non-professional students aged 11-16 who had no professional background and who were completely focused on their secondary education. For them, dance was perhaps a hobby or a bodybuilding exercise. In

\section{ABSTRACT}

Nowadays, dance education has been popularised at different educational levels, so dance teachers have the opportunity to teach students of different ages and backgrounds. However, this created a problem for me as, although I was teaching different people, I did not alter my teaching style. The pedagogy which aimed to foster professional dancers had no effect to nonprofessional students. In order to combine my experiences and resolve my problem, this paper concentrates on the difference between school-based and vocational dance pedagogy.

my classes, I taught the students two dances which did not match their level of skill and which had some movements which were beyond them. Furthermore, I conducted the courses utilising a traditional training pedagogy similar to the way my teacher taught me in a professional dance school. Moreover, this pedagogy is formulaic so there was no creativity or passion; I placed all my focused on performance and technique. Although this method tends to achieve good outcomes in professional dance classes, it is almost certainly not suitable for non-professional students. I overlooked different pedagogies for students with diverse abilities so the teaching outcome could not meet the predetermined requirements.

This experience prompted me to consider the various aspects and objectives of non- professional dance, schoolbased dance pedagogy and vocational dance pedagogies $^{[11]}$. Various pedagogies are available depending on the

*Corresponding Author:

Yingying $\mathrm{Hu}$,

Chengdu Vocational University of Art, Chengdu, Sichuan, 611433, China;

E-mail:3217631571@qq.com. 
different educational contexts, purposes and objects to be implemented in the variety of dance classes in the UK. In order to combine my experiences and resolve my problem, this paper concentrates on the difference between school-based and vocational dance pedagogy. Specifically, any type of dance education which does not aim to foster professional dancers, and which is not full-time dance education, is included in non- professional dance education. School-based dance, which is a form of non- professional dance, refers to dance education in primary and secondary schools and vocational dance refers to dance education in vocational schools and this is full-time dance education ${ }^{[1]]}$. Moreover, I will also consider how I can produce my own pedagogy to teach Chinese students.

Although there are diverse opinions within the literatures, the main direction, which school-based dance use midway model and vocational dance is full-time training model, is generally consistent ${ }^{[20]}$. In order to be more persuasive, the paper will use the national curriculum in England as a vital foundation and standard for understanding school-based dance ${ }^{[8]}$. Meanwhile, the two different pedagogies will be explained through understanding, analysing, refining, combining and summarising the research theories and then clearly highlighting any differences. Finally, these theories and opinions will be adapted to my situation to produce more appropriate pedagogies.

\section{Literature Review}

\subsection{What Is School-Based Dance Pedagogy?}

School-based dance involves dance education in primary and secondary schools. In this paper, however, only secondary dance education is considered. Therefore, all references here to school-based dance relate to secondary dance education. According to the national curriculum in England $^{[8]}$, dance should be taught as part of PE in secondary schools. As a compulsory subject, PE aims to develop students' confidence and interest in exercise and physical activities whether in or out of school ${ }^{[8]}$. At the same time, students will gain an awareness of the importance of physical activity for their health and they will learn how to strengthen their physique through physical activity ${ }^{[8]}$. There are two Key Stages in secondary education - Key Stage 3 and Key Stage 4. During these stages, pupils should be taught different strategies in order to overcome obstacles or solve problems, be encouraged to enjoy and succeed in the many forms of physical activity, and develop their technique and performance ${ }^{[8]}$. Moreover, pupils need to achieve their personal best through self-evaluation and use dance techniques in various styles and forms ${ }^{[20]}$. From the guiding principles, it is clearly perceptible that the course does not aim to cultivate professional dancers. This does not mean that dance techniques and performance skills are not important in themselves; rather, it is to emphasise their importance in fostering other abilities. However, Connell argues that since dance is not treated as a separate subject but as part of PE, there is not enough concentration on dance education and its creativity and dance tends to be a subsidiary discipline ${ }^{[6]}$. Additionally, according to the Audit of Dance Provision ${ }^{[6]}$, most dance courses in schools are led by non-specialists and only $7 \%$ of dance teachers in schools are specialists. This may have some influence on dance pedagogy which must accommodate the series of guiding principles. Therefore, the following discussion of the nature of school-based dance pedagogy will be conducted with these guiding principles in mind.

Specific to dance classes, and in accordance with Smith-Autard, the midway pedagogy is necessary as a main pedagogy in secondary dance courses ${ }^{[20]}$. It closes the gap between educational dance and professional dance with a combination of educational and professional modules. Moreover, it highlights the three strands of creating, performing and appreciating an important dance experience for pupils ${ }^{[20]}$. In a secondary school dance context, the three process will move towards the discipline of choreography, public performance and a critical appreciation of artistic, aesthetic and cultural qualities ${ }^{[12][20]}$. Meanwhile, it concentrates on balancing five contradictory aspects to construct the new pedagogy, the midway model. These aspects are process and product; creativity, imagination, individuality and knowledge of theatre dance; feeling and objective ends; principles and dance techniques; and guided teaching and directed teaching ${ }^{[20]}$. Firstly, the balance between process and product needs teachers to pay equal attention to an individual's learning process and outcome, not only focusing on styled and skilled performances but also respecting their personalities and self-expression. As Smith-Autard argues, a sufficiently prolonged process tends to achieve rich outcomes ${ }^{[20]}$. However, if only the process is emphasised, the scope and depth of exploration will not be sufficient for further learning. Therefore, teachers should pay equal attention to them.

Secondly, it is vital to balance free expression and theatre dance knowledge in class ${ }^{[20]}$. Knowledge of theatre dance is a condition for creativity, imagination and individuality of expression. Students can creatively respond and learn from theatre dance which not only allows them to gain an understanding of theatre dance, but it also nurtures their creativity ${ }^{[6]}$. Teachers need to clearly deliver the fixed part to lead to a better understanding ${ }^{[1]}$. Meanwhile, theatre knowledge could be utilised as a stimulating start- 
ing point from which to promote further creation.

Thirdly, in the midway pedagogy, there is an inextricable link between intuitions and knowledge ${ }^{[20]}$; through various feeling experiences, pupils can acquire knowledge. In addition, in the process of creation, performance and appreciation, feeling experiences need to be encouraged as much as possible by teacher tasks. Meanwhile, teachers should ensure that students have sufficient feelings and perceptions to incorporate them into dance. On the other hand, the body as an instrument should be refined and fashioned for the purpose of art. For instance, if pupils create for themselves, using the natural movements of their bodies, the movements would not be technically refined or advanced enough to be acceptable on an 'art' leve ${ }^{[18-19]}$. Especially for younger secondary students, if teachers do not appropriately equilibrate feeling and training, students may show more feelings than techniques in their dance.

Fourthly, for a combination of movement principles and stylised techniques, the former is fixed and the latter is fluid ${ }^{[2]}$. For fixed part, movement principles as the content source of dance outcomes are crucial. Specified dance techniques as the fluid part are also indispensable as they can drive students to expend their natural movement vocabularies using their own scope of knowledge. Students can freely find their own ways to compose their dance works and they can express their diversity by utilising partnership concepts, special relationship concepts and time concepts ${ }^{[4]}$. Specifically, pupils need to explore and make motifs from actions such as arching, carling, stretching, rocking and rolling ${ }^{[20]}$. The type of action is defined but the detail depends on the individually stylised techniques.

Fifthly, there is a focus on guided teaching and directed teaching. According to Smith- Autard, the midway model requires teachers to moderately intervene with students but they cannot make pupils feel that they are deprived of their ownerships ${ }^{[3][7][20]}$. As guides, teachers lead students to solve problems and promote themselves. Smith-Autard claims that: 'In my opinion, at this stage in education, the teacher needs to intervene in about eighty per cent of problem-solving occasions in order that the student responses to tasks progress and develop in range and variety. ${ }^{, 20]}$ This viewpoint is useful for dance teachers because a specific standard is provided for their teaching.

Overall, due to the educational purpose, the midway model is full of creativity. It demonstrates the combination of fixed and fluid ${ }^{[1]}$, creativity and knowledge, self-expression and training, movement principles and stylised techniques, and guided teaching and directed teaching. Although it is regarded as a balance, I think that the fluid part may be more than the fixed part during the classroom due to the teaching purpose. Moreover, the midway model allows training and learning to be flexible and creative; students have enough space and time for self-development while their personalities are respected and their creativity obtains support from the teacher. Therefore, this model will be utilised to bring students into a teaching environment in which the fixed and fluid parts are distributed according to their personalities and abilities ${ }^{[1]}$. The three strands of composing, performing and appreciating will be conducted in individuals, pairs, groups and teams to promote students' cooperative and coordinating abilities. By applying the midway model, dance education will provide sufficient opportunities for students to demonstrate and improve on their creative skills ${ }^{[6]}$. Meanwhile, it can also be effective for students' development in other subjects ${ }^{[6]}$. More importantly, secondary dance education can improve self-esteem and attainment, enhance citizenship values and allow students to obtain a perception of other cultures ${ }^{[6]}$.

\subsection{What Is Vocational Dance Pedagogy?}

'When most people think of careers in dance, two possibilities immediately spring to mind: dancing professionally and teaching ${ }^{,[11]}$. Vocational dance involves the type of dance education that is aimed at cultivating professional dancers for choruses, dance companies and theatres ${ }^{[1]}$. In contrast to educational dance pedagogy, the aim decides the pedagogy; professional dance pedagogy caters to demand. Combining Smith-Autard's theories concerning professional dance with the purpose of vocational dance education, this paper will define vocational dance pedagogy ${ }^{[20]}$.

Firstly, vocational dance pedagogy focuses on product rather than process as it has the specific aim of fostering professionals for choruses, dance companies and theatres $^{[11]}$. Generally, dancers attend an intensive and professional training course from the age of ten. Technique and artistic sensibility are crucial traits so the first step must involve professional training as this is the basis of a performance career ${ }^{[11]}$. In addition, most vocational schools test their students through dance presentations, and theatre, company and chorus auditions so the professional pedagogy will be weighted too heavily towards product and outcome ${ }^{[11]}$. In order to achieve a skilled body performance, students need teachers to focus on only one technique in the time available ${ }^{[20]}$.

Secondly, the pedagogy clearly pays more attention to knowledge of theatre dance while the absence of creativity is a common aspect of vocational schools. Many books and articles have repeatedly emphasised that vocational 
dancers require full- time courses, a high level of training and long-term learning ${ }^{[11][14-15]}$. This type of pedagogy may be short of creativity and flexibility because of its high demand for quality of movement. As students, we must follow our teachers' steps to develop our professional competence. For instance, vocational ballet education always concentrates on two areas - ballet vocabulary and training ${ }^{[14]}$. As the subject is completely taught by teachers, students do not have any opportunities for dialogue or dissension ${ }^{[14]}$. This results in an absence of creativity. Indeed, in most vocational schools, training occupies the primary proportion of the available timetable. In addition to a ballet class, a choreographic class is conducted with a prescribed formula to be learned and employed in a vocational context ${ }^{[15]}$. Consequently, there will probably be an absence of creativity, imagination and individuality, and students generally neglect the expressive aspects of dance in vocational dance classes ${ }^{[14]}$. However, there are exceptions especially in contemporary dance education, creativity gains relatively more development space. For instance, the UK Centre for Advanced Training (CATs), a government-funded pre-vocational dance training programme for talented dancers, nurtures individual ability while finding and developing outstanding performers and choreographers, providing an ideal setting for nurturing creativity ${ }^{[21]}$.

Thirdly, the balance between feeling and training in a vocational context almost certainly depends on dance styles. Technique classes generally focus on training but there is a difference between ballet classes and contemporary dance classes. Specifically, the feeling in a contemporary dance class can be more than in a ballet class. However, generally, training obtains more attention than feeling. As Chrisstated: 'The circumstances and nature of this intensive training will depend on the individual's ability and previous dance experience, but invariably, it demands several hours of dance practice a day, several days a week ${ }^{,[11]}$. Similarly, Pulinkala explains the situa$\operatorname{tion}^{[15]}$. This clearly indicates the importance of training for vocational dancers in vocational dance education. The fixed part takes precedence over the fluid part so feeling will appear infrequently in vocational dance contexts ${ }^{[1]}$.

Fourthly, in the professional context, most student dancers focus only on one dance style which limits their diversity. Meanwhile, as Smith-Autard states, techniques are necessarily involved in a technique class because of the need for a specific range of movement and promoting performance with a specialist style ${ }^{[20]}$. Technique classes in a normal vocational dance context are divided into two parts - performing exercise and dance sequence. The former provides training for students to strengthen their strength, flexibility, balance, posture, alignment, coordination and stamina. The latter teaches them how to bring expression into movement by utilising qualities such as rhythm, phrasing, dynamics, spatial patterning and style $^{[20]}$. Although there is an emphasis on technique, pupils need to learn a set of movement vocabularies and the style of the technique, no matter what the dance.

Fifthly, professional dance education generally employs directed teaching to convey knowledge and technique. Furthermore, a professional instructor is essential to teach the professionals of the future. Thus teachers need to master a range of knowledge and movement. Morris introduced the phrase 'teacher-centred manner' in vocational pedagogies ${ }^{[14]}$. As directing guides, teachers always use 'correct' and 'wrong' to assess students because there is only one correct 'answer' to the way to perform movements.

Using five aspects, this paper illustrates the meaning of professional dance pedagogy. These statements reveal the reality that mostly vocational dance schools and teachers overvalue technique and skills, and students' creativity and personalities are regarded as insignificant. Thus, many scholars and teachers are beginning to discuss the importance of creativity in professional dance schools.

\subsection{What Is the Difference between School-Based Dance Pedagogy and Vocational Dance Pedagogy?}

The above analysis reveals that the most obvious difference is the balance between the fixed and fluid parts ${ }^{[1]}$. The former includes technique, theatre knowledge, training, movement principles and the directed teaching method while the latter involves creativity, imagination, personality, self- expression, stylised techniques and guided teaching. Thus, there is a comparison to be made between school-based pedagogy, creative teaching, vocational pedagogy and traditional training.

Due to their different educational purposes, the creativity factor holds a different position in the two pedagogies. In a secondary context, there is a relatively equal balance between the fixed and fluid parts and creativity tends to be essential in lessons ${ }^{[3]}$. However, in the vocational context, creativity is always ignored and teachers value the fixed part. The development of professional skills is dominant but other abilities including creativity, cooperation, coordination, organisation and leadership receive insufficient development. Therefore, the two pedagogies appear to generate respective distinctions. Many articles discuss the situation, absence of creativity, in vocational schools. Scholars and teachers are increasingly aware of the importance of creativity whether it is in school-based dance education or vocational dance education. Over and above 
these main differences, there are some common aspects between the two pedagogies.

\subsection{What are their common aspects?}

There are some perspectives of dance pedagogy which are common to school-based dance and vocational dance. A large amount of enthusiasm, dedication and perseverance is required by teachers of dance because their hard work will influence their pupils ${ }^{[9]}$. This is equally important in the two educational contexts of secondary schools and vocational schools. Moreover, in the fixed part, teacher demonstration is important in both pedagogies. When teachers instruct students about movement or knowledge, they should pay attention to seven key points including breaking the material down into appropriate levels, showing the movement as they described it, descriptive language, asking questions, peer feedback and The speed of delivering knowledge, as well as continually promoting level of task ${ }^{[9]}$. These are all common aspects of dance education. Through understanding and analysis, I will endeavour to discover the most appropriate dance pedagogy for me.

\section{More appropriate dance pedagogy}

\subsection{School-based dance pedagogy}

Due to the educational aim, the midway approach, which combines educational dance and professional dance, is reasonable and scientific for secondary students. However, the ability to control a classroom is crucial because secondary pupils are full of energy, vitality and creativity. If a teacher cannot properly manage a classroom, it may become disorderly and chaotic. As Beghetto and Kaufmann discuss, teachers should decide which part of the lesson will be more fixed and which part may be more fluid ${ }^{[1]}$. The fluid part needs to remain fixed to ensure development and the teacher should be flexible in terms of how they teach different students. At the same time, 'inside-out' and 'outside-in' is crucial for pedagogy, especially outside and inside dialogue. This relationship will effectively drive students' creativity ${ }^{[4]}$. The majority of school-based dance prefers to give priority to 'inside-out', because they focus on fostering creativity. However, for some overactive students, 'outside-in' may be an appropriate method at that time. Therefore, if I am teaching secondary students or non-professional students, I will use the midway model and plan the lesson in terms of the students' physical ability. Combining my previous teaching experience, I will be more flexible and creative in the subsequent class which will allow my students to be more devoted, interested, enthusiastic and creative. Integrated development will be regarded as a main purpose ${ }^{[13]}$.

\subsection{Vocational dance pedagogy}

According to various articles, vocational dance pedagogy generally lacks creativity. Therefore, more creativity should be respected in the vocational context. The midway approach is a good example for vocational dance education. Vocational pedagogy can combine the midway model but still emphasise technique. A teacher should provide opportunities for students to express themselves, show creativity and develop imagination ${ }^{[5][16]}$. Teacher evaluation is important but peer feedback is also crucial. Teachers should not only teach movements, techniques, skills and knowledge, they should also encourage learning. Pupils should be able to gain a better self-awareness through the planned lesson. Furthermore, teachers should use imaginative teaching methods to teach students how to be creative; they should regard creativity as one of the main teaching purposes to develop a creative teaching method $^{[10]}$. In addition, question-posing can effectively build a creative and imaginative environment for students to develop creativity ${ }^{[2]}$. Moreover, the opinion of Melchior is useful for teachers as, although the background to her research involves a primary classroom, the main thread of her argument is suitable for both educational dance pedagogy and professional dance pedagogy ${ }^{[13]}$. In her opinion, teachers need to plan and conduct lessons having regard to the students' backgrounds and personalities so that language and cultural background are not barriers to learning and development. Having different cultural backgrounds and language is a universal phenomenon in education so teachers should adapt culturally responsive dance pedagogy in the classroom.

\section{Conclusion}

Through above analysis and comparison, this paper not only explains the two dance pedagogies, it also reveals and compares their differences. Due to different purposes, pedagogy is obviously different between schoolbased context and vocational context. The former is more creative, flexible and free, but the latter is more stylized, formalistic. The former values individuality and does not ignore fixed knowledge, the latter focuses on technique but sometimes neglects creativity and self-expression. By utilising the analysis and combining my experience and opinion, some advice and considerations are presented. In addition, the analysis and my subsequent understanding have allowed me to clearly understand how to use different pedagogies when teaching a variety of diverse students. I believe that creativity is vital no matter what the 
educational context. Therefore, I will continually consider creativity and incorporate it into my learning and teaching.

\section{References}

[1] Beghetto, R. and Kaufmann, J. Teaching for creativity with disciplined improvisation. In Sawyer, R.K. (ed.) Structure and improvisation in creative teaching $[\mathrm{M}]$. New York: Cambridge University Press, 2011 .

[2] Chappell, K., Craft, A., Burnard, P., et al. Question-posing and Question-responding: the heart of 'Possibility Thinking' in the early years[J]. Early Years, 2008,28 (03):267-286.

[3] Chappell, K., Rolfe, L., Craft, A., et al. Journeys of becoming: humanising creativity. In: Chappell, K. (ed.) Close Encounters Dance Partner for Creativity[M]. London: Trentham Books Limited,2011.

[4] Chappell, K., Rolfe, L., Craft, A. et al. The development of partnership-based pedagogies. In: Rolfe, L. (ed.) Close Encounters Dance Partner for Creativity[M]. London: Trentham Books Limited,2011.

[5] Chappell, K., Craft, A.R., Rolfe, L. et al.Humanizing creativity: Valuing our journeys of becoming $[\mathrm{J}]$. International Journal of Education \& the Arts, 2012,13 (8).

[6] Connell, J. Dance education: an examination of practitioners' perceptions in secondary schools and the necessity for teachers skilled in the pedagogy and content of dance $[\mathrm{J}]$. Research in Dance Education, 2009,10 (02) :115-130.

[7] Craft, A., McConnon, L. Matthews, A. Creativity and child-initiated play: fostering possibility thinking in four-year-olds $[\mathrm{J}]$. Thinking Skills and Creativity, 2012,7 (01): 48-61.

[8] DfE. Physical Education: The National Curriculum for England [EB/OL]. http://www.education.gov.uk/ schools/teachingandlearning/curriculum/secondary/ b001 98952/pe [Accessed: 16 October 2014].

[9] Gough, M. Planning a dance course. In: Gough, M. (ed.) Knowing dance[M]. London: Dance Books Ltd,1999.
[10] Jeffrey, B. and Craft, A. Teaching Creatively and Teaching for Creativity: distinctions and relationships[J]. Educational Studies, 2004,30 (01):77-87.

[11] Jones, Chris. Dance! : Education, Training and Careers[M]. Guildford: National Resource Centre for Dance, 1994.

[12] McFee, G. Dance within physical education. In: McFee, G. (ed.) The Concept of Dance Education[M]. London: Routledge, 1994.

[13] Melchior, E. Culturally responsive dance pedagogy in the primary classroom. Research in Dance Education, 2011,12 (02):119-135.

[14] Morris, G. Problems with ballet: step, style and training[J]. Research in Dance Education, 2010,4 (01) $: 17-30$.

[15] Pulinkala, I. (2011) Integration of a professional dance into college[J]. Research in Dance Education,2011,12 (03) :259-275.

[16] Rolfe, L. Fostering Creativity in Dance Education. In: Sanders, L. (ed.) Dance Teaching and Learning: Shaping Practice[M]. London: Youth Dance England,2012.

[17] Sanders, L. Learning theories (part 1): Overview. In: Sanders, L. (ed.) Dance Teaching and Learning: Shaping Practice[M]. London: Youth Dance England,2012.

[18] Sanders, L. Learning theories (part 2): Motor Learning Theory and Dance Teaching. In: Sanders, L. (ed.) Dance Teaching and Learning: Shaping Practice[M]. London: Youth Dance England,2012.

[19] Sanders, L. Teaching styles. In: Tomkins, A. (ed.) Dance Teaching and Learning: Shaping Practice[M]. London: Youth Dance England, 2012.

[20] Smith-Autard, J. The Art of Dance in Education[M]. $2^{\text {nd }}$ ed. London: A \& C Black,2002.

[21] Watson, D.E., Nordin-Bates, S.M., et al. Facilitating and nurturing creativity in pre-vocational dancers: Findings from the UK Centres for Advanced Training[J]. Research in Dance Education, 2012,13 (02):153-173. 